\title{
Can the blood pressure predict cognitive task performance in a healthy population sample?
}

Citation for published version (APA):

van Boxtel, M. P. J., Gaillard, C., Houx, P. J., Buntinx, F., de Leeuw, P., \& Jolles, J. (1997). Can the blood pressure predict cognitive task performance in a healthy population sample? Journal of Hypertension, 15(10), 1069-1076. https://doi.org/10.1097/00004872-199715100-00004

Document status and date:

Published: 01/01/1997

DOI:

10.1097/00004872-199715100-00004

Document Version:

Publisher's PDF, also known as Version of record

\section{Please check the document version of this publication:}

- A submitted manuscript is the version of the article upon submission and before peer-review. There can be important differences between the submitted version and the official published version of record.

People interested in the research are advised to contact the author for the final version of the publication, or visit the DOI to the publisher's website.

- The final author version and the galley proof are versions of the publication after peer review.

- The final published version features the final layout of the paper including the volume, issue and page numbers.

Link to publication

\footnotetext{
General rights rights.

- You may freely distribute the URL identifying the publication in the public portal. please follow below link for the End User Agreement:

www.umlib.nl/taverne-license

Take down policy

If you believe that this document breaches copyright please contact us at:

repository@maastrichtuniversity.nl

providing details and we will investigate your claim.
}

Copyright and moral rights for the publications made accessible in the public portal are retained by the authors and/or other copyright owners and it is a condition of accessing publications that users recognise and abide by the legal requirements associated with these

- Users may download and print one copy of any publication from the public portal for the purpose of private study or research.

- You may not further distribute the material or use it for any profit-making activity or commercial gain

If the publication is distributed under the terms of Article $25 \mathrm{fa}$ of the Dutch Copyright Act, indicated by the "Taverne" license above, 


\section{Can the blood pressure predict cognitive task performance in a healthy population sample? \\ Martin P. J. van Boxtel, Carlo Gaillard*, Peter J. Houx, Frank Buntinx ${ }^{\dagger}$, Peter W. de Leeuw ${ }^{\ddagger}$ and Jelle Jolles}

Objectives To study the relation between the blood pressure and the neurocognitive function within the full adult age range in a large population sample.

Design A cross-sectional study of $\mathbf{9 3 6}$ healthy adults who were recruited from a register of family practices, stratified for age (24-81 years), sex, and occupational level, who took part in a medical and neurocognitive test program.

Methods The blood pressure status was studied in relation to five measures of cognitive ability, including verbal memory and speed of information processing. Other vascular risk factors were treated as control variables and included smoking, alcohol intake, body mass index, and body fat distribution. The blood pressure was measured five times using an automatic recording technique (with a Dinamap 8100 device).

Results After adjustment for age, sex, and educational level in a hierarchical regression analysis, we found no unequivocal association between the mean systolic and diastolic blood pressures (or any other studied vascular risk factor) and cognitive test performance both for the whole group and for the subgroup of subjects who were not being administered antihypertensive medication and whose medical history did not include cardiovascular events. Stratified analysis within four age levels revealed no age-specific associations between the blood pressure

\section{Introduction}

The integrity of cognitive abilities is vital for old people to maintain their independence, and any potential risk factor for cognitive decline against which one could intervene warrants careful evaluation. In recent years it has been a matter of debate whether the blood pressure status contributes independently to the impairment of the cognitive function that comes with age. Hypertension has been associated with atherosclerotic changes in large and small cerebral blood vessels and a reduction in autoregulation of cerebral blood flow [1,2], and is a major risk factor for strokes and vascular dementia. Clinically 'silent' whitematter lesions in hypertensive subjects have been observed by neuroimaging and may be associated with decrements in cognitive functioning [3,4]. Most casecontrol studies have reported a functional impairment of the central nervous system in hypertensive subjects, as and the cognitive function. Subjects whose blood pressure was within the hypertensive range performed worse than did matched controls at letter digit copying, but not according to other cognitive measures.

Conclusions With a population-based sample unselected for blood pressure status we found no linear relationship between the actual blood pressure level and various aspects of cognitive performance. Prospective studies are needed to investigate the possibility that the systemic blood pressure load over time is associated with a decline in specific cognitive abilities.

\section{Journal of Hypertension 1997, 15:1069-1076}

Keywords: blood pressure, cognitive function, aging, methodology

From the Department of Psychiatry and Neuropsychology, Maastricht University, the *Department of Internal Medicine, Eemland Hospital, Amersfoort, the ${ }^{\dagger}$ Department of General Practice, Maastricht University, and the ₹Department of Internal Medicine, Maastricht University, The Netherlands.

Sponsorship: This study was supported in part by a grant from the Dutch Ministries of Education and Health \& Welfare, via the Steering Committee for Gerontological Research (Nestor). It is part of the Maastricht Aging Study (MAAS).

No reprints are to be made available.

Received 9 December 1996 Revised 2 June 1997 Accepted 6 June 1997

(C) Rapid Science Publishers ISSN 0263-6352

assessed with neuropsychologic tests [5-12], but differences between hypertensive and normotensive individuals were not observed in all individual tests or in all studies [13]. The deficiencies that were most consistently associated with hypertension were found in memory function, attentional capacity, abstract reasoning, and speed of response [13-15]. Longitudinal data suggest that cognitive decline over time is more pronounced among hypertensives than it is among normotensive control subjects [5], although other investigators found no difference in the rate of change in cognitive scores related to the subject's hypertensive status [16,17]. However, from a clinical perspective the between-group differences are small and not very specific.

Population-based studies on this issue have produced mixed results. In the Framingham Heart Study, 2123 
subjects aged 55-89 years were tested with a short cognitive screening battery [18]. After adjustment for the effects of age, sex, education, vascular risk factors (smoking, alcohol intake), and use of antihypertensive medication, no relation between the diastolic or systolic blood pressure (measured once or twice) and cognitive performance scores was found. However, when information from previous biennial control visits on the blood pressure status and use of antihypertensive medication was taken into consideration, an inverse relation between the cognitive compound score on the one hand, and the proportion of blood pressure measurements within the hypertensive range and overall mean systolic and diastolic blood pressures on the other was found for subjects who had not been treated with antihypertensive medication [19]. Reanalysis of these data revealed an inverse relation between historical mean blood pressure levels and the overall cognitive performance [20]. The midlife level of the systolic - but not diastolic - blood pressure in the 4678 surviving male members of the Honolulu-Asia Aging Study (mean age 78 years) was related negatively to the score in a cognitive screening test 25 years later, independently of age, education, cardiovascular disease, and subclinical atherosclerosis [2]. In a recent Italian study, the diastolic - but not systolic - blood pressure level in 1339 subjects aged $65-95$ years was associated with cognitive impairment [a Mini-Mental Status Examination (MMSE) score below 24] but only among subjects aged 75 years and over, after the authors had controlled for age, sex, education, depressive symptomatology, and antihypertensive treatment [21]. The subjects in that study were free from neurologic diseases but included in their number institutionalized subjects: nearly $30 \%$ of the study group consisted of cognitively impaired people (MMSE score $<24)$. By taking pathologic cognitive decline as an outcome measure, it was demonstrated recently in a longitudinal study of 382 nondemented subjects who were aged 70 years at baseline that higher systolic and diastolic blood pressures were associated with the development of dementia 10-15 years later [22]. However, the authors of that study did not control for the educational level and socioeconomic status of their subjects, which factors may affect the risks both of hypertension and of dementia, and thereby mediate the association between hypertension and dementia. Finally, in a large crosssectional study of 1642 subjects aged 75-101 years an inverse association between the blood pressure and dementia was demonstrated [23].

The issue becomes more complex when the factor age is considered. It has been suggested that the blood pressure accounts for the variance in measures of cognitive performance that otherwise would be ascribed simply to aging [24]. The prevalence both of hypertension and of cognitive impairment rises with age. Conversely, the cerebral blood flow is known to decline markedly with age, and the structural changes in the brain associated with hyper- tension may cause cerebral ischemia [1], thereby aggravating the age-related cognitive decline indirectly $[3,8]$. On the other hand, some evidence from cross-sectional studies $[2,18,24]$ indicates that an elevated blood pressure is beneficial for the cognitive status of older subjects by promoting cerebral blood flow. Thus, because the prevalence of vascular risk factors (including a blood pressure within the hypertensive range) and the development of vascular pathology and end-organ damage are related intricately to age and sex, it is important to control these variables in any study of the relation between vascular risk factors and the cognitive function. This study was intended to examine the relation between the repeatedly measured blood pressure and the performance in tests of global and specific cognitive functioning with a large adult population sample, with rigorous adjustment for the factors age, sex, and educational background. Other vascular risk factors (smoking behavior, alcohol intake, body mass index, and fat distribution) were included in the analysis as potentially confounding variables [25].

\section{Methods \\ Subjects}

The study population consisted of 943 subjects who participated between March 1993 and February 1995 in the Maastricht Aging Study (MAAS) [26]. This cohort of community-dwelling adults was recruited in two waves from a register of 15 local family practices that contained 60000 patients [27]. Registration as a patient of a general practice is compulsory in The Netherlands so that each citizen is administered medical care and therefore the register can be considered an unselected population sample. The subjects were invited to take part in the study in an introductory letter from their general practitioners. The first half of the study sample was drawn from the group of 3744 subjects that had been recruited from the register, in order to satisfy the requirements of a postal survey into health and memory-related functions. This group was stratified for sex and age (into 12 classes, of subjects aged $25 \pm 1$ years, $30 \pm 1$ years, and so on up to $80 \pm 1$ years, each of at least 310 subjects). Of this group $2362(63.1 \%)$ subjects agreed to participate and 2043 (54.6\%) returned the postal questionnaire in good order: $1252(33.4 \%)$ of these respondents volunteered for an additional medical and cognitive test program, for which 468 subjects were selected randomly, again stratified for sex, age class, and, additionally, two levels of occupational achievement. The latter procedure was intended to stratify beforehand the level of general ability [26]. For the second wave a group of 2047 subjects was selected from the register in order to replicate the first-wave study exactly, using the same design and methodology, but without an independent postal survey. Of this group 676 (33.0\%) subjects agreed to participate in the test program, of whom 475 were actually tested. The remainder of the volunteers were included in a third wave of the MAAS, which is not described here. Data for seven subjects for 
whom we had incomplete cognitive data were excluded from the analysis, which resulted in a final sample size of 936.

Participating and nonparticipating groups did not differ with respect to the number of medical problems and the presence of chronic diseases recorded by their general practitioners. Noncomplying subjects in the first step of recruitment were found more often in the youngest and oldest age classes, were less well educated, and were more often women [26].

Subjects with past or present morbidity generally associated with brain dysfunction, namely overt cerebrovascular disease (including those who had suffered a stroke), chronic neurologic diseases (e.g. dementia, epilepsy, and Parkinson's disease), mental retardation, and psychotropic drug use, were not included. This reduced the eligible population in the register by $4 \%$. In addition, subjects who had been invited to participate in the test program were screened for possible dementia with the MMSE [28]. Thirteen subjects who scored below the clinical cut-off score of 24 were excluded before entering the test program. Subject characteristics are summarized in Table 1. The study protocol was approved by the ethics committee of the Academic Hospital, Maastricht, and all of the participants gave their informed consent to participate in the study.

\section{Measurements}

\section{Background characteristics}

The questionnaire that was filled in by all of the participants covered background characteristics, including education (on an eight-point scale, ranging from primary education to university degree [29]) and an extensive health history. A structured medical interview preceded the actual test session, to check the questionnaire inform- ation and the eligibility for the study. Tobacco use and alcohol intake were scored as dichotomous variables [present or past smoking: yes/no; alcohol intake of less/ more than 21 (women) or 35 (men) standard units per week [30]). More specifically, subjects with medically confirmed cardiovascular morbidity [a cardiovascular event (CVE), including angina pectoris, cardiac arrhythmia, myocardial infarction, cardiac insufficiency, valvular lesions, heart surgery, resuscitation, and evidence of peripheral atherosclerosis] and those who were being administered antihypertensive medication were identified. The prevalence of these characteristics is shown in Table 1.

\section{Physical measurements}

The body height and weight of each subject were measured to calculate the body mass index (BMI, in $\mathrm{kg} / \mathrm{m}^{2}$ ). In addition, the waist and hip circumference was determined, the waist : hip ratio (WHR) being used as an independent vascular risk factor [31]. During the $30 \mathrm{~min}$ intermission between two test blocks the blood pressure was recorded five times, with fixed intervals of $5 \mathrm{~min}$. Measurements were made on the left arm with a Critikon Dinamap 8100 monitor (Critikon, Tampa, Florida, USA) that was equipped with the appropriately sized arm cuff. During blood pressure measurements the subjects were seated, did not smoke or drink caffeine-containing beverages and were left unattended by the researcher after careful instruction. The averages of five consecutive measurements was taken as the habitual systolic and diastolic blood pressures.

\section{Cognitive assessment}

Standard neuropsychologic tests were used to assess the cognitive domains general intelligence, memory, sensorimotor speed, and information processing speed/cognitive flexibility [26], which are described briefly below.

Table 1 Main independent and dependent variables used in this study, by levels of age (regrouped into six classes) and sex (presented cognitive outcome measures are population-based, Z-transformed scores)

\begin{tabular}{|c|c|c|c|c|c|c|c|c|}
\hline & \multicolumn{6}{|c|}{ Age class (years) } & \multicolumn{2}{|c|}{ Sex } \\
\hline & $\begin{array}{c}25-30 \\
(n=161)\end{array}$ & $\begin{array}{c}35-40 \\
(n=162)\end{array}$ & $\begin{array}{c}45-50 \\
(n=162)\end{array}$ & $\begin{array}{c}55-60 \\
(n=159)\end{array}$ & $\begin{array}{c}65-70 \\
(n=162)\end{array}$ & $\begin{array}{c}75-80 \\
(n=130)\end{array}$ & $\begin{array}{c}\text { Men } \\
(n=475)\end{array}$ & $\begin{array}{l}\text { Women } \\
(n=461)\end{array}$ \\
\hline Men/women & $81 / 80$ & $81 / 81$ & $80 / 82$ & $81 / 78$ & $81 / 81$ & $71 / 59$ & & \\
\hline Diastolic blood pressure $(\mathrm{mmHg})$ & $67 \pm 8$ & $71 \pm 10$ & $75 \pm 10$ & $76 \pm 11$ & $76 \pm 11$ & $76 \pm 12$ & $76 \pm 10$ & $71 \pm 11$ \\
\hline Systolic blood pressure $(\mathrm{mmHg})$ & $119 \pm 11$ & $120 \pm 11$ & $126 \pm 14$ & $133 \pm 17$ & $142 \pm 19$ & $147 \pm 21$ & $133 \pm 17$ & $128 \pm 20$ \\
\hline Hypertension* & 5 & 11 & 23 & 39 & 67 & 62 & 118 & 89 \\
\hline Waist : hip ratio & $0.81 \pm 0.08$ & $0.84 \pm 0.09$ & $0.86 \pm 0.10$ & $0.88 \pm 0.08$ & $0.90 \pm 0.08$ & $0.90 \pm 0.07$ & $0.91 \pm 0.07$ & $0.81 \pm 0.08$ \\
\hline Body mass index $\left(\mathrm{kg} / \mathrm{m}^{2}\right)$ & $24.8 \pm 3.9$ & $25.6 \pm 3.8$ & $27.0 \pm 5.5$ & $27.1 \pm 3.6$ & $27.9 \pm 4.1$ & $27.6 \pm 3.5$ & $26.7 \pm 4.0$ & $26.5 \pm 4.6$ \\
\hline Smokers (past/actual) & 87 & 124 & 123 & 102 & 98 & 88 & 365 & 257 \\
\hline High alcohol intake (actual) & 3 & 7 & 9 & 8 & 1 & 4 & 14 & 18 \\
\hline Antihypertensive drug use & 1 & 1 & 16 & 26 & 51 & 59 & 76 & 78 \\
\hline CVE & 1 & 6 & 7 & 25 & 48 & 57 & 92 & 52 \\
\hline CVE/antihypertensive drug use & 2 & 7 & 18 & 39 & 74 & 76 & 119 & 97 \\
\hline Memory & $0.56 \pm 0.76$ & $0.47 \pm 0.76$ & $0.10 \pm 0.78$ & $0.01 \pm 0.84$ & $-0.40 \pm 0.91$ & $-0.91 \pm 0.87$ & $-0.26 \pm 0.95$ & $0.27 \pm 0.87$ \\
\hline Sensorimotor speed & $0.65 \pm 0.43$ & $0.47 \pm 0.45$ & $0.25 \pm 0.54$ & $-0.08 \pm 0.64$ & $-0.47 \pm 0.69$ & $-1.00 \pm 0.81$ & $-0.01 \pm 0.79$ & $0.03 \pm 0.82$ \\
\hline Cognitive flexibility & $0.67 \pm 0.45$ & $0.51 \pm 0.53$ & $0.28 \pm 0.65$ & $-0.09 \pm 0.67$ & $-0.49 \pm 0.76$ & $-1.13 \pm 0.89$ & $-0.04 \pm 0.87$ & $0.07 \pm 0.89$ \\
\hline Letter/Digit Substitution Test & $0.90 \pm 0.70$ & $0.56 \pm 0.74$ & $0.25 \pm 0.78$ & $-0.19 \pm 0.71$ & $-0.63 \pm 0.78$ & $-1.12 \pm 0.72$ & $-0.08 \pm 0.96$ & $0.08 \pm 1.03$ \\
\hline Word fluency & $0.42 \pm 0.94$ & $0.31 \pm 0.94$ & $0.18 \pm 0.97$ & $-0.15 \pm 0.97$ & $-0.31 \pm 0.97$ & $-0.57 \pm 0.82$ & $-0.03 \pm 1.01$ & $0.03 \pm 0.99$ \\
\hline
\end{tabular}

Values are expressed as means $\pm \mathrm{SD}$ and numbers of subjects. ${ }^{*}$ Diastolic blood pressure $\geqslant 90 \mathrm{mmHg}$ or systolic blood pressure $\geqslant 140 \mathrm{mmHg}$ CVE, cardiovascular event. 
Four subtests of the Groningen Intelligence Test (GIT) were used to obtain an estimation of the full-scale intelligence quotient [32].

The Word Learning Task (WLT) is based upon the Auditory Verbal Learning Test [33] and evaluates the ability to acquire and retain new verbal information. A set of 15 frequently used monosyllabic words is presented in fixed order at a rate of one every $2 \mathrm{~s}$ in each of five trials. After every trial the subject is asked to reproduce the memorized words (immediate recall). Twenty minutes after the last trial the subject is asked again to reproduce the set of words (delayed recall). The total of correctly reproduced words during five trials, the maximum score in five trials, and the number of correctly reproduced words after $20 \mathrm{~min}$ are recorded.

The Concept Shifting Task (CST) is a test of behavioral planning and is analogous to the Trail-Making-Test of the Army Individual Test Battery [34]. The subject's ability to alternate two psychologic concepts during task performance is measured (i.e. number and letter cancellation in correct order). A test sheet contains 16 smalldiameter $(15 \mathrm{~mm})$ circles arranged in a larger circle (diameter $16 \mathrm{~cm}$ ). Two null versions (part 0) contain no symbols in the circles, the number version (part A) presents the numbers $1-16$ in random order in the circles, a letter version (part B) depicts randomly the letters A-P, and finally a number-letter version (part $\mathrm{C}$ ) alternates the numbers 1-8 and letters $\mathrm{A}-\mathrm{H}$. The subject is instructed to cross out the circles in correct order, as fast as possible without making errors. The outcome is the time needed to complete each task.

Susceptibility to perceptual interference was measured by using the Stroop Color Word Test (SCWT), consisting of three subtasks; color word naming (I), color naming (II), and naming of color words printed in a different color (interference task III). This test detects robust effects of chronologic age [35].

The Letter/Digit Substitution Test (LDST) is a modified version of the paper-and-pencil Symbol Digit Modalities Test [36] and measures the basic informationprocessing speed. The subject is requested to copy numbers in cells that are indexed by a letter. The letter refers to nine letter-number pairs in a key at the top of the form. The total number of corresponding numbers correctly copied in $90 \mathrm{~s}$ is recorded.

Word Fluency was scored as the total number of animal names reproduced correctly in $60 \mathrm{~s}$ [32]. The test reflects the organizational level among clusters of meaningful related words.

\section{Data reduction and analysis}

To limit the number of dependent variables and to improve the robustness of the underlying cognitive construct [37,38], the relevant raw test scores were clustered in three compound performance indices, labelled memory, cognitive flexibility, and sensorimotor speed. Raw scores were transformed to standardized $Z$ scores for the total group $[Z=(\mathrm{X}-\overline{\mathrm{X}}) / \mathrm{SD}]$. Next, we averaged $\mathrm{Z}$ scores from tests that had been included in the compound performance index: the memory score was derived from the total, maximal, and delayed recall scores of the WLT; the cognitive flexibility score included the $\mathrm{C}$ version of the CST and subtask III of the SCWT [39]; and the sensorimotor speed was calculated from the $0, \mathrm{~A}$, and B versions of the CST, and subtask I of the SCWT. Thus, the memory score was calculated as $\left(Z_{\text {WLTTOT }}+\right.$ $\left.Z_{\text {WLTMAX }}+Z_{\text {WLTDEL }}\right) / 3$, the cognitive flexibility score as $-\left(Z_{\text {CST-C }}+Z_{\text {SCWT-III }}\right) / 2$, and the sensorimotor speed score as $-\left(Z_{\text {CST- } 0}+Z_{\text {CST-A }}+Z_{\text {CST-B }}+Z_{\text {SCWT-I }}\right) / 4$. The signs of the speed and flexibility scores were made negative to make them reflect above-average performance when positive and below-average performance when negative. LDST and fluency test outcomes were also transformed to $Z$-scores but not included in compound scores because the performance in these tests is less domain-specific.

Multiple hierarchical regression analysis was used to estimate the strength of associations between predictor variables and the performance in cognitive outcome measures. After we had controlled for chronological age, sex, and education in the first step, the various vascular risk factors and their respective age-risk-factor interaction terms with age were entered as pairs in the regression models in order to detect an increase in explained variance in cognitive performance measures. The predictor variables tested were the systolic and diastolic blood pressures, BMI, WHR, alcohol intake, smoking behavior, antihypertensive drug use, and presence of CVE in the medical history. Separate models were fitted for the total group and for the group of subjects free from CVE and not being administered antihypertensive medication $(n=720)$.

Next, subjects were classified hypertensive when they had a diastolic blood pressure $\geqslant 90 \mathrm{mmHg}$ or a systolic blood pressure $\geqslant 140 \mathrm{mmHg}$ [40]. All of the hypertensive subjects thus identified were matched for age (in years), sex, and educational level with normotensive controls. Between-group differences were tested with Student's paired t tests. $P<0.05$ was considered statistically significant, unless indicated otherwise

\section{Results}

Table 1 provides descriptive statistics of the predictor variables and the cognitive outcome measures, by levels of age, class, and sex.

Zero-order correlations between predictor variables and cognitive outcome measures are presented in Table 2. All of the cognitive parameters were correlated negatively to 
Table 2 Zero-order correlations among age, sex, educational level, vascular risk factors and cognitive parameters

\begin{tabular}{|c|c|c|c|c|c|c|c|c|c|}
\hline & Age & $\mathrm{Sex}^{+}$ & $\begin{array}{c}\text { Intelligence } \\
\text { quotient }\end{array}$ & Education & Memory & $\begin{array}{l}\text { Sensori } \\
\text { motor } \\
\text { speed }\end{array}$ & $\begin{array}{c}\text { Cognitive } \\
\text { flexibility }\end{array}$ & LDST & Fluency \\
\hline Age & & & & & $-0.50^{*}$ & $-0.67^{*}$ & $-0.65^{\star}$ & $-0.68^{*}$ & $-0.34^{*}$ \\
\hline Sex & -0.02 & & & & $0.28^{*}$ & 0.03 & 0.06 & 0.08 & 0.03 \\
\hline Intelligence quotient & $0.12^{\star}$ & $-0.21^{*}$ & & & $0.11^{*}$ & $0.24^{*}$ & $0.27^{\star}$ & $0.27^{*}$ & $0.36^{*}$ \\
\hline Education & $-0.39^{*}$ & -0.07 & $0.48^{*}$ & & $0.35^{*}$ & $0.46^{*}$ & $0.47^{\star}$ & $0.48^{*}$ & $0.36^{*}$ \\
\hline Diastolic blood pressure & $0.26^{*}$ & $-0.25^{\star}$ & 0.07 & $-0.10^{\star}$ & $-0.17^{\star}$ & $-0.17^{\star}$ & $-0.16^{\star}$ & $-0.21^{*}$ & $-0.11^{*}$ \\
\hline Systolic blood pressure & $0.55^{\star}$ & $-0.13^{*}$ & 0.07 & $-0.24^{\star}$ & $-0.30^{*}$ & $-0.40^{\star}$ & $-0.38^{\star}$ & $-0.41^{*}$ & $-0.21^{*}$ \\
\hline Pulse pressure & $0.51^{*}$ & 0.02 & 0.05 & $-0.21^{*}$ & $-0.26^{*}$ & $-0.38^{*}$ & $-0.37^{\star}$ & $-0.37^{*}$ & $-0.18^{*}$ \\
\hline Body mass index & $0.24^{\star}$ & -0.03 & -0.05 & $-0.20^{*}$ & $-0.17^{\star}$ & $-0.16^{*}$ & $-0.18^{\star}$ & $-0.18^{*}$ & $-0.10^{*}$ \\
\hline Waist : hip ratio & $0.36^{*}$ & $-0.55^{\star}$ & $0.10^{*}$ & $-0.18^{\star}$ & $-0.35^{\star}$ & $-0.26^{\star}$ & $-0.27^{\star}$ & $-0.30^{*}$ & $-0.18^{*}$ \\
\hline Alcohol intake ${ }^{\ddagger}$ & -0.01 & 0.03 & 0.04 & 0.04 & 0.03 & 0.02 & 0.03 & 0.03 & 0.04 \\
\hline Smoking behavior ${ }^{\neq}$ & 0.01 & $-0.22^{*}$ & $0.10^{*}$ & -0.02 & $-0.09^{*}$ & 0.03 & 0.01 & 0.01 & 0.05 \\
\hline Antihypertensive medication & $0.41^{*}$ & 0.01 & 0.03 & $-0.14^{*}$ & $-0.22^{*}$ & $-0.28^{*}$ & $-0.27^{\star}$ & $-0.30^{*}$ & $-0.17^{\star}$ \\
\hline Cardiovascular events ${ }^{\ddagger}$ & $0.40^{*}$ & $-0.11^{*}$ & $0.11^{\star}$ & $-0.10^{*}$ & $-0.26^{*}$ & $-0.23^{*}$ & $-0.25^{\star}$ & $-0.26^{*}$ & $-0.10^{*}$ \\
\hline
\end{tabular}

${ }^{\star} P \geqslant 0.01$ (two-tailed test). LDST, Letter/Digit Substitution Test. ${ }^{\dagger} 0$, male; 1 , female; ${ }^{\ddagger} 0$, no, 1 , yes

age (from -0.34 to -0.68 ), and positively, but to a lesser extent, with the educational level (0.35-0.48) and general intelligence $(0.11-0.36)$. The relatively high correlations of cognitive parameters to educational level may in part be explained in terms of the -0.39 correlation between age and education. The systolic and diastolic blood pressures, BMI, WHR, antihypertensive medication use, and CVE in the medical history were also related negatively to cognitive scores, but again such associations can be mediated by the factor age.

The associations between vascular risk factors and the risk factor-age interaction with the five cognitive scores (memory, sensorimotor speed, cognitive flexibility, letter digit copying, and fluency), were tested in separate multiple hierarchical regression analyses, after we had adjusted for age, sex, and educational level. When the BMI, WHR, smoking, alcohol intake, antihypertensive medication use, and CVE in the medical history were entered together with their respective interactionwith-age term in the regression models, no significant additional variance in cognitive outcome measures was explained by these factors. For this reason these variables were not included as control variables in the final models in which the blood pressure and the blood pressure-age interaction were tested as predictors of the cognitive outcome.

The separate models fitted for the diastolic and systolic blood pressures showed that the variables chronological age, sex, and educational level explained between $17 \%$ (word fluency) and 50\% (letter/digit copying) of the variance in cognitive scores, age being the most important predictor. No association between the blood pressure and cognitive parameters was observed in the models after step 2. However, in the model for the systolic blood pressure the age-blood pressure interaction term was associated negatively with two speed indices, the sensorimotor speed and cognitive flexibility. There was no noticeable change in the size and direction of the observed effects when the entry of blocks was reversed and age was entered in the last block of variables, or when the analyses were repeated for the subgroup of subjects with no history of CVE and not being administered antihypertensive drugs. Table 3 summarizes the results of regression analysis for the systolic blood pressure both for the total

Table 3 Results of multiple hierarchical regression analyses of cognitive outcome variables

\begin{tabular}{|c|c|c|c|c|c|c|c|}
\hline & \multicolumn{3}{|c|}{ Step 1} & \multicolumn{2}{|c|}{ Step 2} & \multicolumn{2}{|c|}{$\mathrm{R}^{2}$ after step } \\
\hline & Age & Sex & Education & SBP & Age $\times$ SBP & 1 & 2 \\
\hline \multicolumn{8}{|l|}{ All subjects } \\
\hline Memory & $-0.40^{\star \star \star}$ & $0.30^{\star \star \star}$ & $0.21^{\star \star \star}$ & 0.05 & $-0.08^{*}$ & $0.331^{\star \star \star}$ & $0.336^{*}$ \\
\hline Sensorimotor speed & $-0.57^{\star \star \star}$ & $0.05^{\star}$ & $0.24^{\star \star \star}$ & 0.03 & $-0.11^{\star \star \star}$ & $0.478^{\star \star \star}$ & $0.487^{\star \star \star}$ \\
\hline Cognitive flexibility & $-0.54^{\star \star \star}$ & $0.10^{\star \star \star}$ & $0.28^{\star \star \star}$ & 0.03 & $-0.10^{\star \star \star}$ & $0.485^{\star \star \star}$ & $0.493^{\star \star *}$ \\
\hline Letter/digit copying & $-0.55^{\star \star \star}$ & $0.09^{* \star *}$ & $0.26^{\star \star \star}$ & -0.01 & -0.02 & $0.498^{\star * \star}$ & 0.499 \\
\hline Word fluency & $-0.22^{\star \star \star}$ & 0.06 & $0.28^{\star \star \star}$ & 0.00 & -0.03 & $0.173^{\star \star \star}$ & 0.174 \\
\hline \multicolumn{8}{|c|}{ CVE/medication-free subjects } \\
\hline Memory & $-0.35^{\star * *}$ & $0.29^{* \star *}$ & $0.25^{\star \star \star}$ & 0.02 & $-0.07^{*}$ & $0.302^{\star * *}$ & 0.306 \\
\hline Sensorimotor speed & $-0.54^{\star \star \star}$ & 0.05 & $0.25^{\star \star \star}$ & 0.00 & $-0.11^{\star \star \star}$ & $0.456^{\star * \star}$ & $0.467^{\star \star \star *}$ \\
\hline Cognitive flexibility & $-0.51^{\star \star \star}$ & $0.11^{\star \star \star}$ & $0.31^{\star \star \star}$ & -0.02 & $-0.10^{\star \star \star}$ & $0.489^{\star \star \star}$ & $0.499^{* * *}$ \\
\hline Letter/digit copying & $-0.50^{\star \star \star}$ & $0.09^{\star \star}$ & $0.26^{\star \star \star}$ & -0.05 & -0.03 & $0.466^{\star \star \star}$ & 0.469 \\
\hline Word fluency & $-0.21^{\star \star \star}$ & $0.08^{\star \star}$ & $0.28^{\star \star \star}$ & 0.03 & -0.02 & $0.157^{\star \star \star}$ & 0.158 \\
\hline
\end{tabular}

Shown are standardized regression coefficients $(\beta)$, the significance level of the unstandardized regression coefficient $(B)$ in the final model, $\mathrm{R}^{2}$ (the proportion of explained variance), and the significance of the change in $\mathrm{R}^{2}$ after each step. Different models were fitted for all subjects $(n=936)$ and for subjects free from cardiovascular events and not being administered antihypertensive drugs $(n=720)$. ${ }^{\star} P \leqslant 0.05,{ }^{\star \star} P \leqslant 0.01$, ${ }^{\star * \star} P \geqslant 0.001$. SBP, systolic blood pressure; CVE, cardiovascular event. 
Table 4 Characteristics of subjects whose blood pressure was within the hypertensive range (diastolic blood pressure $\geqslant 90 \mathrm{mmHg}$ or systolic blood pressure $\geqslant 140 \mathrm{mmHg}, \mathrm{n}=191$ ) compared with normotensive controls from this sample, matched for chronological age, sex, and educational level (78 subjects in both groups were female)

\begin{tabular}{lcc}
\hline & $\begin{array}{c}\text { Control } \\
\text { group }\end{array}$ & $\begin{array}{c}\text { Hypertensive } \\
\text { group }\end{array}$ \\
\hline Age (years) & $63.1 \pm 12.7$ & $63.1 \pm 12.7$ \\
Education & $2.8 \pm 1.6$ & $2.8 \pm 1.6$ \\
Intelligence quotient & $115.7 \pm 13.5$ & $113.9 \pm 13.1$ \\
Body Mass Index $\left(\mathrm{kg} / \mathrm{m}^{2}\right)$ & $27.2 \pm 3.6$ & $28.2 \pm 3.9^{*}$ \\
Waist : hip ratio & $0.90 \pm 0.07$ & $0.91 \pm 0.07$ \\
Diastolic blood pressure $(\mathrm{mmHg})$ & $70.0 \pm 8.9$ & $84.7 \pm 10.2^{\star \star \star}$ \\
Systolic blood pressure $(\mathrm{mmHg})$ & $124.6 \pm 8.9$ & $155.2 \pm 15.9^{\star \star \star}$ \\
Memory & $0.02 \pm 0.93$ & $-0.01 \pm 0.96$ \\
Sensorimotor speed & $0.05 \pm 0.82$ & $-0.03 \pm 0.76$ \\
Cognitive flexibility & $0.12 \pm 0.84$ & $-0.02 \pm 0.86$ \\
Letter/digit copying & $0.09 \pm 1.03$ & $-0.10 \pm 0.96^{\star}$ \\
Word fluency & $0.07 \pm 0.93$ & $-0.07 \pm 1.06$
\end{tabular}

Values are expressed as means $\pm S D$. Cognitive measures are expressed as population-based, Z-transformed scores. ${ }^{\star} P \leqslant 0.05,{ }^{\star \star} P \leqslant 0.01,{ }^{\star \star *} P \leqslant 0.001$.

group and for the selection of subjects free from CVE who had not been administered antihypertensive drugs $(n=720)$. Results for the diastolic blood pressure are not shown here but were virtually identical up to step 1 .

The contribution of the blood pressure to the regression models was small (it explained at most $1.0 \%$ of the additional variance in the cognitive flexibility score, for the systolic blood pressure in subjects of the unmedicated and CVE-free group). However, the observed age-systolic blood pressure interactions suggested that there was an age-dependency in the blood pressure-cognitive performance relationship. It was therefore decided to perform identical regression analyses for the data in four age strata: 25-35 years, 40-50 years, 55-65 years, and 70-80 years. No association between the systolic blood pressure and any of the five cognitive variables was observed for any age stratum, using the same adjustments for background variables as in earlier analyses.

In an attempt to replicate earlier findings of cognitive deficits in patient groups with clinical hypertension, the subjects whose blood pressure was within the hypertensive range, on the basis of the mean of laboratory values, were matched with normotensive controls for calendar age, sex, and educational level. Of 207 thusidentified hypertensive subjects (diastolic blood pressure $\geqslant 90 \mathrm{mmHg}$ or systolic blood pressure $\geqslant 140 \mathrm{mmHg}$ [40]), 191 were matched in this way. The cognitive scores of this subgroup were again rescaled to a $Z$ distribution: the two groups are compared in Table 4. Paired Student's t tests revealed a higher mean BMI for the group with hypertension. Furthermore, hypertensive subjects performed worse at letter/digit copying, but no significant between-group differences were observed with other cognitive measures.

\section{Discussion}

Vascular risk factors were studied in relation to several aspects of cognitive performance in an adult population, stratified for age, sex, and general ability. This was done in order to separate the effect on cognitive processes of factors that may be linked to cerebrovascular pathology from the effect of primary aging. We found weak inverse associations between the age-systolic blood pressure interaction term on the one hand, and two measures of the information-processing speed (the sensorimotor speed and cognitive flexibility) on the other. Neither the blood pressure status nor any other vascular risk factor, however, was associated with the cognitive performance, after we had accounted for the variance explained by age, sex, and educational level. The same observation was made after age-stratified analysis: again the blood pressure status did not explain unique variance, indicating that there was no age-dependent relationship between the blood pressure and cognitive test scores. Finally, hypertensive subjects performed worse at letter/digit copying than did age-, sex-, and education-matched controls with normal blood pressures, which partly confirms earlier observations of cognitive performance deficits in hypertensive individuals. However, we found no other between-group differences in cognitive outcome. Before any conclusions can be drawn several methodologic issues need to be addressed.

\section{Blood pressure measurement}

To determine the blood pressure status accurately we measured the blood pressure in a standard environment [41]. More importantly, the blood pressure was measured in the absence of an observer to minimize the response of the blood pressure in some individuals which might have occurred as a result of an alerting reaction (the whitecoat effect [42]). In this respect, single or duplicate blood pressure measurement by classical sphygmomanometry is particularly error-prone, because an observer is present to record the blood pressure. Nevertheless, sphygmomanometry has been used in most of the studies reviewed here $[4,18,20,43]$, which might have resulted in estimates of the habitual blood pressure less precise than those in this study.

However, averaging all five consecutive blood pressure measurements does not take into account that the blood pressure tends to habituate during a measurement interval. Indeed, subjects who had been screened in the first wave of this study tended to have lower blood pressures at the end of the 20 min measurement session [44]. It was suggested that the habitual blood pressure was reflected better by the average of the final two measurements. For this reason additional post-hoc analyses were performed using the averages of the last two systolic and diastolic blood pressure measurements, reflecting the blood pressure after adaptation, as predictors of performance. The resulting regression models 
were, however, not substantially different from those based on the average of five measurements.

\section{Cognitive status measurement}

We chose to combine raw test scores into compound measures of the neurocognitive function that had been employed in earlier research. Although this choice was based on theoretical and statistical considerations, this procedure might seem to some extent arbitrary in the choice of variables measuring the same underlying cognitive ability. It could therefore be important to note here that post-hoc analyses of the raw scores derived from the cognitive tests as the outcome measures produced essentially the same results as did the analyses of compound measures.

\section{Blood pressure and the cognitive function}

Earlier research suggested that the educational level of a subject can moderate the association between the blood pressure and the cognitive performance [45]. We found no evidence with our sample that the relationship between the blood pressure and the cognitive function was education-dependent: the blood pressure-educational level interaction term was not predictive of the cognitive outcome in any model (post-hoc analysis, results not shown). However, the educational level of the participants was higher than that of nonparticipants, which could have attenuated cognitive differences between groups with high and low mean blood pressures in the study sample, if there were any.

Subjects with manifest neurological diseases or MMSE scores below 24 were not subjected to the test program, because the MAAS does not focus primarily on pathologic cognitive dysfunctions, such as dementia. Instead we intended to identify determinants of normal (or 'usual') cognitive aging. Results from a recent study by Cacciatore et al. [21] showed that, for a much older sample (subjects aged 65-95 years) with evidently more true cognitive pathology (30\% scored below the MMSE cut-off score of 24), an elevated diastolic blood pressure was related to lower scores on the MMSE. These findings would suggest that defining our population as we did prevented our finding an association between the blood pressure and the cognitive function due to a 'restriction of range' with respect to cognitive abilities and vascular pathology. However, when studying usual cognitive aging it is important to exclude subjects with possible dementia because it is still not known whether usual cognitive aging and dementia are on the same continuous scale [46].

It could be argued that, in some respects, the crosssectional nature of this study could compromise the generalizability of our findings. The blood pressure status was based on repeated blood pressure measurements during a single session and no reliable information was available about the subjects' blood pressure status on previous occa- sions in order to estimate the systemic blood pressure 'load' over time. This notion is important in the light of earlier findings that in fact the blood pressure load, rather than the blood pressure level at the time of cognitive testing, was associated with cognitive decline in later life $[2,20]$. The actual blood pressure level is at best only a weak predictor of the lifetime blood pressure load, particularly when therapeutic intervention has preceded the measurement. Furthermore, selective participation of individuals whose vascular system has remained relatively uncompromised, who may therefore have a lower risk of cognitive impairment, might have biased our sample. Bias of this kind could obscure the true impact of an elevated blood pressure on the cognitive performance and reduce the generalizability of our findings. It is reassuring in this respect that participants did not differ from nonparticipants with regard to prevalent morbidity recorded by the family physician [26]. These limitations, however, apply to any cross-sectional study on this subject and can be overcome only by using a longitudinal study design.

Our data do not corroborate the findings of Elias et al. [24], who, in a study of 301 healthy subjects, aged 20-72 years, found negative correlations between systolic and diastolic blood pressures within the normal-to-hypertensive range and performances in complex cognitive tests, after adjustment for age, sex, and educational level. Subjects with hypertension were encouraged by their physicians to participate in the study, which could have resulted in the proportion of hypertensive individuals being larger than that in the present study. Indeed, as Elias et al. [24] pointed out, there may be subtle neurocognitive differences between hypertensive and normotensive individuals, but we found no relationship in our study between the performance in cognitive tests and the blood pressure treated as a continuous variable.

The presence of cardiovascular disease has been associated with cognitive deficits in some studies [6,9]. Administration of antihypertensive medication and CVE both index a wide variety of different vascular morbidity subtypes. It seems obvious that excluding subjects with one or more of these characteristics from the analysis would reduce the prevalence of vascular pathology in the remaining group, including the prevalence of subclinical cerebrovascular damage. However, neither administration of antihypertensive medication nor CVE was associated with the cognitive function in this study, suggesting that the impact of such conditions on cognitive abilities is small in an independently living sample.

In conclusion, the evidence we found of cognitive disturbances as a function of the blood pressure status is at best weak: one index of the information-processing speed (the LDST) indicated a lower performance among hypertensive subjects, but we found no linear relationship between the mean blood pressure level and the cognitive 
outcome. From these data we can not conclude that the actual blood pressure level is an important mediator of cognitive dysfunctions in a normal aging population unselected with respect to the blood pressure status. Further research needs to focus on longitudinal follow-up of cohorts such as this to test the hypothesis that the decline in function in specific cognitive domains is a function of the blood pressure 'load' over time in more detail.

\section{References}

1 Starr JM, Whalley $\amalg$ : Senile hypertension and cognitive impairment: an overview. J Hypertens 1992, 10 (suppl):S31-S42.

2 Launer LJ, Masaki K, Petrovitch H, Foley D, Havlik RJ: The association between midlife blood pressure levels and late-life cognitive function: the Honolulu-Asia Aging Study. JAMA 1995, 274:1846-1851.

3 Van Swieten JC, Geyskes GG, Derix MMA, Peek BM, Ramos LMP, van Latum JC, et al:: Hypertension in the elderly is associated with white matter lesions and with cognitive decline. Ann Neurol 1991, 30:825-830.

4 Breteler MBB, van Swieten JC, Bots ML, Grobbee DE, Claus JJ, van den Hout JHW, et al:: Cerebral white matter lesions, vascular risk factors, and cognitive function in a population-based study: The Rotterdam Study. Neurology 1994, 44:1246-1252.

5 Wilkie FL, Eisdorfer C: Intelligence and blood pressure in the aged. Science 1971, 172:959-962.

6 Spieth W: Cardiovascular health status, age, and psychological performance. J Gerontol 1964, 19:277-284.

7 Goldman H, Kleinman KM, Snow MY, Bidus DR, Korol B: Correlation of diastolic blood pressure and signs of cognitive dysfunction in essential hypertension. Dis Nerv Syst 1974, 35:571-572.

8 Boller F, Vrtunski PB, Mack JL, Kim Y: Neuropsychological correlates of hypertension. Arch Neurol 1977, 34:701-705.

9 Herzog C, Schaie KW, Gribbin K: Cardiovascular disease and changes in intellectual functioning from middle to old age. J Gerontol 1978, 33:872-883.

10 Shapiro AP, Miller RE, King HE, Ginchereau EH, Fitzgibbon K: Behavioral consequences of mild hypertension. Hypertension 1982, 4:355-360.

11 Madden DJ, Blumenthal JA: Slowing of memory-search performance in men with mild hypertension. Health Psychol 1989, 8:131-142.

12 Battersby C, Hartley K, Fletcher AE, Markowe HJL, Brown RG, Styles W, et al:: Cognitive function in hypertension: a community based study. J Hum Hypertens 1993, 7:117-123.

13 Waldstein SR, Manuck SB, Ryan CM, Muldoon MF: Neuropsychological correlates of hypertension: review and methodological considerations. Psychol Bull 1991, 110:451-469.

14 King HE, Miller RE: Hypertension: cognitive and behavioral considerations. Neuropsychol Rev 1990, 1:31-73.

15 Waldstein SR: Hypertension and neuropsychological function: a lifetime perspective. Exp Aging Res 1995, 21:321-352.

16 Elias MF, Schultz JNR, Robbins MA, Elias PK: A longitudinal study of neuropsychological performance by hypertensives and normotensives: a third measurement point. J Gerontol 1989, 44:25-28.

17 Schultz NR Jr, Elias MF, Robbins MA, Streeten DHP, Blakeman N: A longitudinal study of the performance of hypertensive and normotensive subjects on the Wechsler Adult Intelligence Scale. Psychol Aging 1989, 4:496-499.

18 Farmer ME, White LR, Abbott RD, Kittner SJ, Kaplan E, Wolz MM, et al.: Blood pressure and cognitive performance: the Framingham study. Am J Epidemiol 1987, 126:1103-1114.

19 Farmer ME, Kittner SJ, Abbott RD, Wolz MM, Wolf PA, White LR: Longitudinally measured blood pressure, antihypertensive medication use, and cognitive performance: the Framingham Study. J Clin Epidemiol 1990, 43:475-480.

20 Elias MF, Wolf PA, D'Agostino RB, Cobb J, White LR: Untreated blood pressure level is inversely related to cognitive functioning: the Framingham Study. Am J Epidemiol 1993, 138:353-364.

21 Cacciatore F, Abete P, Ferrara N, Paolisso G, Amato L, Canonico S, et al: The role of blood pressure in cognitive impairment in an elderly population. J Hypertens 1997, 15:135-142.

22 Skoog I, Lernfelt B, Landahl S, Palmertz B, Andreasson L-A, Nilsson L, et al.: 15-Year longitudinal study of blood pressure and dementia. Lancet 1996, 347:1141-1145.
23 Guo Z, Viitanen M, Fratiglioni L, Winblad B: Low blood pressure and dementia in elderly people: the Kungsholmen project. BMJ 1996, 31:805-808.

24 Elias MF, Robbins MA, Schultz JNR, Pierce TW: Is blood pressure an important variable in research on aging and neuropsychological test performance? J Gerontol 1990, 45:P128-P135.

25 Starr JM, Whalley LJ: Senile hypertension and cognitive impairment. J Hypertens 1992, 10 (suppl):S31-S42.

26 Jolles J, Houx PJ, van Boxtel MPJ, Ponds RWHM: Maastricht Aging Study: Determinants of Cognitive Aging. Maastricht: Neuropsych Publishers; 1995.

27 Metsemakers JFM, Höppener P, Knottnerus JA, Kocken RJJ, Limonard CBG: Computerized health information in the Netherlands: a registration network of family practices. $\mathrm{Br} J$ Gen Pract 1992 , 42:102-106.

28 Folstein MF, Folstein SE, McHugh PR: 'Mini Mental State'. J Psychiat Res 1975, 12:189-198.

29 De Bie SE: Standaardvragen 1987: Voorstellen voor uniformering van vraagstellingen naar achtergrondkenmerken en interviews. Leiden: Verenigde Onderzoeks Instituten; 1987.

30 World Heath Organization: Problems Related to Alcohol Consumption. Geneva: World Health Organization; 1980.

31 Despres JP, Moorjani S, Lupien PJ, Tremblay A, Nadeau A, Bouchard C: Regional distribution of body fat, plasma lipoproteins, and cardiovascular disease. Arteriosclerosis 1990, 10:497-511.

32 Luteijn F, van der Ploeg FAE: Handleiding Groninger Intelligentietest (GIT). Lisse, The Netherlands: Swets and Zeitlinger; 1983.

33 Brand N, Jolles J: Learning and retrieval rate of words presented auditory and visually. J Gen Psychol 1985, 112:201-210.

34 Houx PJ, Vreeling FW, Jolles J: Age-associated cognitive decline is related to biological life events. In Alzheimer's Disease: Basic Mechanisms, Diagnosis and Therapeutic Strategies. Edited by lqbal K, McLachlin DRC, Winblad B, Wisniewski HM. Chichester: Wiley; 1991:353-358.

35 Houx PJ, Jolles J, Vreeling FW: Stroop interference: aging effects assessed with the Stroop Color-Word test. Exp Aging Res 1993, 19:209-224.

36 Smith A: The Symbol Digit Modalities Test: a neuropsychological test for economic screening of learning and other cerebral disorders. Learning Disorders 1968, 36:83-91.

37 Houx PJ, Jolles J: Vulnerability factors for age-related cognitive decline. In Toxins in Air and Water. Edited by Isaacson RL, Jensen KF. New York: Plenum Press; 1994:25-41.

38 Van Boxtel MPJ, Langerak K, Houx PJ, Jolles J: Self-reported physical activity, subjective health, and cognitive performance in older adults. Exp Aging Res 1996, 22:363-379.

39 LaRue A: Aging and Neuropsychological Assessment. New York: Plenum Press; 1992.

40 World Health Organization and International Society of Hypertension: 1993 Guidelines for the management of mild hypertension: memorandum from a World Health Organization/International Society of Hypertension meeting. J Hypertens 1993, 7:689-693.

41 Pickering TG: Ambulatory Monitoring and Blood Pressure Variability. London: Science Press; 1991.

42 Mancia G, Casadei R, Groppelli A, Parati G, Zanchetti A: Effect of stress on diagnosis of hypertension. Hypertension 1991, 17 (suppl III): 56-62.

43 Starr JM, Whalley $\amalg$, Inch S, Shering PA: Blood pressure and cognitive function in healthy old people. J Am Geriatr Soc 1993, 41:753-756.

44 Van Boxtel MPJ, Gaillard C, van Es PN, Jolles J, de Leeuw PW: Repeated automatic versus ambulatory blood pressure measurement: the effects of age and sex in a normal ageing population. $J$ Hypertens 1996, 14:31-40.

45 Elias MF, Robbins MA, Schultz NR Jr, Streeten DH, Elias PK: Clinical significance of cognitive performance by hypertensive patients. Hypertension 1987, 9:192-197.

46 Jorm AF: A method for measuring dementia as a continuum in community surveys. In: Dementia and Normal Aging. Edited by Huppert FA, Brayne C, O'Connor DW. Cambridge: Cambridge University Press; 1994:244-253. 